\title{
Kinematic Modelling of FES Induced Sit-to-stand Movement in Paraplegia
}

\author{
Mohammed Ahmed ${ }^{1}$, M. S. Huq ${ }^{2}$, B. S. K. K. Ibrahim ${ }^{3}$ \\ ${ }^{1,2,3}$ Department of Mechatronic and Robotic Engineering, Faculty of Electrical and Electronics Engineering (FKEE), \\ Universiti Tun Hussein Onn Malaysia (UTHM), 86400 Parit Raja, Johor, Malaysia \\ ${ }^{1,2,3}$ Advanced Mechatronic Research Group (AdMiRe), Faculty of Electrical and Electronic Engineering, Universiti Tun \\ Hussein Onn Malaysia (UTHM), 86400 Parit Raja, Johor, Malaysia \\ ${ }^{1}$ Department of Electrical and Electronics Engineering, Faculty of Engineering and Engineering Technology (FEET), \\ Abubakar Tafawa Balewa University (ATBU), P. M. B. 0248 Bauchi, Bauchi State, Nigeria
}

\begin{tabular}{l}
\hline \hline Article Info \\
\hline Article history: \\
Received Aug 23, 2017 \\
Revised Nov 10, 2017 \\
Accepted Nov 24, 2017 \\
\hline
\end{tabular}

\section{Keyword:}

FES-induced movement

Kinematic model

Nervous system disorders

Rehabilation robotics

Sit-to-stand movement

\begin{abstract}
FES induced movements from indication is promising due to encouraging results being obtained by scholars. The kinematic model usually constitute the initial phase towards achieving the segmental dynamics of any rigid body system. It can be used to ascertain that the model is capable of achieving the desired goal. The dynamic model builds on the kinematic model and is usually mathematically cumbersome depending on the number of degrees-offreedom. This paper presents a kinematic model applicable for human sit-tostand movement scenario that will be used to obtain the dynamic model the FES induced movement in a later study. The study shows that the 6 DOF conceptualized sit-to-stand movement can be achieved conveniently using 4 DOF. The 4 DOF has an additional joint compared to similar earlier works which makes more it accurate and flexible. It is more accurate in the sense that it accommodates additional joint i.e. the neck joint whose dynamics could be captured. And more flexible in the sense that if future research uncover more contributions by the segments it can be easily incorporated including that of other segments e.g. the trunk, neck and upper limbs.
\end{abstract}

Copyright $\odot 2017$ Institute of Advanced Engineering and Science. All rights reserved.

\section{Corresponding Author:}

Mohammed Ahmed,

Departement of Mechatronic and Robotic Engineering,

Faculty of Electrical and Electronic Engineering,

Universiti Tun Hussein Onn malaysia,

86400 Parit Raja, Batu Pahat, Johor, Malaysia.

Email: inunugoloma@yahoo.com

\section{INTRODUCTION}

Restoring the ability to reestablished movements impaired due occurrence of failure in the nervous system using electrical current is known as functional electrical stimulation (FES). Illnesses and mishaps are the causes of the disorders and could be partial or complete [1-6]. The electrical signals are processed suitable form before being applied to right muscles for initiating the intended movement [2], [4], [7], [8]. Apart from restoring movements, FES is also utilized for rehabilitation (of the neural system) and for therapy as well [9-11]. The trend indicated annual rise in neural disorder subjects [12], [13]. There are in existence low number of assist devices employing FES and this might be due to strict requirements (www.cms.gov/CAG-00153R). Open loop control are popular among the few systems and are characterized by having fixed and built-in commands which are initiated by the user. These constitute weaknesses and can be highly improved using closed loop control techniques that may lead to passing the clinical requirements for FES assisted movements restoration devices [14-16]. 
There are works that further confirm the superiority of the closed loop schemes over the open loop in the case of FES-assisted sit-to-stand [17], [18]. Stability is a very important concern in FES induced movements perhaps it could be one of the important factor hindering clinical acceptance. According to scholars the linear control scheme might not provide solution to the system under consideration in this study (paraplegics i.e. humans with lost neural/movement functions in the lower limbs) due its nonlinear nature [18], [19]. Linear control methods were applied for control of FES-assisted sit-to-stand movements as depicted in the works of Dolan et al. [17], Poboronuic [20], Yu et al. [18], the authors did not indicate mathematical model used even though for linear control schemes the model has to be linearized if it is not linear. The intelligent control schemes were also proposed and some of the works in that regards include that of Davoodi and Andrews [21], [22]. Computer models were used and one of the major shortcomings of the intelligent approach is lack of mathematical model for stability studies. Hence, stability analysis cannot be achieved easily [23] even though the methods used to yield good results. Combined linear and nonlinear methods was proposed by Previdi et al. [24] and nonlinear approaches were presented by Espanjani and Towhidkah [25], also virtual models were used. The advantage of the nonlinear control scheme is that they can be used with nonlinear models which are usually closer to real systems. Additionally, the mathematical models can be used for stability studies.

This study is an initial phase of developing an improved nonlinear model of the FES-assisted sit-tostand movements using the principle of robotics. Involving more joints; which improves accuracy and flexibility, more gray model; combines more experimental and analytical properties and incorporating finding; which portrays that the upper limbs supports about $10 \%$ of the weight. The manuscript was structured such that the introduction gives an overview on the study. Modelling methodology; briefly explain the whole concept employed and was followed by short results explanation referred to as 'results and discussion'. Finally, the conclusion rounds up everything.

\section{MODELLING METHODOLOGY}

Kinematics basically shows the relationship between the link or segment lengths and joint angles of the model, and hence, the coordinates and orientation in space [26], [27]. It yields equations that portray motions of robotic structure without given considerations to the effects of torques and forces, emphases is given to the geometry.

In the modeling relevant robotics principles were applied. The model proposed was based on the works of Nuzik et al. [28], Davoodi and Andrews [21], Yu et al. [18], Kamnik et al. [29], Fattah et al. [30], Tsukahara et al. [31] and Stevermer and Gillette [32]. The sit-to-stand movement was conceptualized as having three phases; the initial, transitional and the final phases. Figure 1(a) and Figure 1(b) were illustrations of the first and last phases respectively. The transition phase is in between the two, which are terminal points in the maneuver. The movement was assume to occur on the sagittal plane, making it a planar motion.
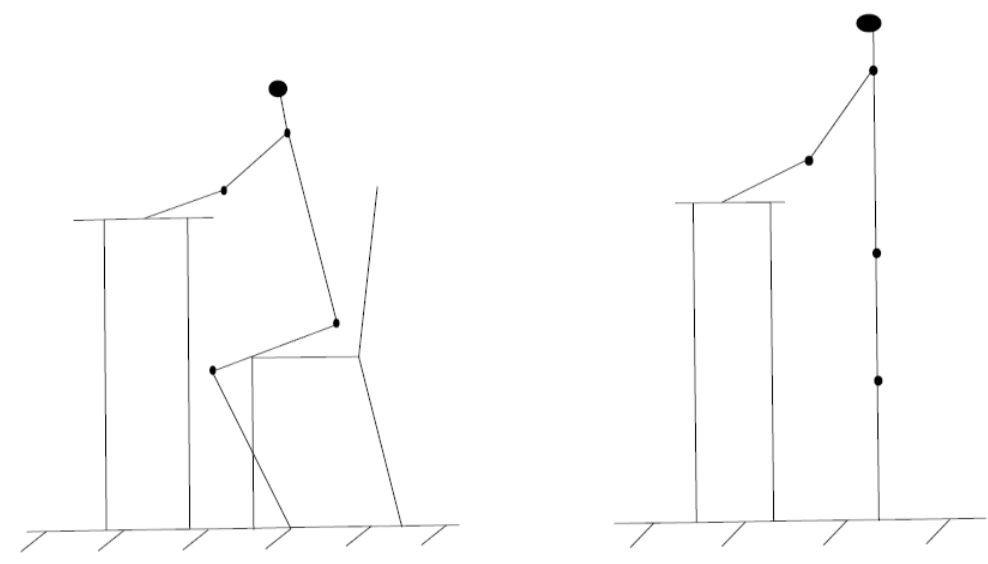

Figure 1. Conceptualized initial and final sit-to-stand positions

The various segment lengths were obtained as described in the works of Winter, [33] which are anthropometry based. Paraplegic subject P3 from the works of Ferrarin and Pedotti, [34] was selected for the study. The segmental lengths are as listed in Table 1.

Kinematic Modelling of FES Induced Sit-to-stand Movement in Paraplegia .... (Mohammed Ahmed) 
Table 1. Segment Lengths of the Paraplegic P3 with Height $178 \mathrm{~cm}$, Weight $85 \mathrm{Kg}$ and Age 25 Years

\begin{tabular}{ccc}
\hline S/No. & Segment & Length $(\mathrm{cm})$ \\
\hline 1 & Shank & 50.7 \\
2 & Thigh & 43.6 \\
3 & Trunk & 51.3 \\
4 & Feet to Support Distance & 30.0 \\
5 & Support & 98.0 \\
6 & Lower Arm & 25.8 \\
7 & Upper Arm & 33.5 \\
8 & Head and Neck & 32.4 \\
\hline
\end{tabular}

In robotics however the manipulators were made up of links and are interconnected by joints forming the entire structure called the kinematic chain. There are basically three types of joints; revolute, prismatic and socket joints. Revolute or rotary joint as the name implies usually give rise to rotation between a pair of links, the prismatic or linear joint is for linear movement between dual adjacent links and the socket joint has the combine properties of the revolute and prismatic joints [35]. The counting of the joints usually starts from zero from the base frame and highest number of the joints gives the degree of freedom (DOF) of the robot for simple planer open loop chain configurations also known as serial configurations. In the case of closed loop chains or combinations of open and closed loop chains the Grübbler's method can be applied [35].The body segments in Figure 1(a) and Figure 1(b) were carefully assigned configurations of links and joint angles as shown in Table 2, which are more appropriate for the next stage of study.

Table 2. Parameters of the Segments

\begin{tabular}{cccc}
\hline Segment & Link & Length $(\mathrm{cm})$ & Angles $\left(\theta_{i}\right)$ \\
\hline Shank & $1_{1}$ & 50.7 & $\theta_{1_{1}}$ \\
Thigh & $1_{2}$ & 43.6 & $\theta_{1_{2}}$ \\
Trunk & $1_{3}$ & 51.3 & $\theta_{1_{3}}$ \\
Feet to Support Distance & $2_{1}$ & 30.0 & $\theta_{2_{1}}$ \\
Support & $2_{2}$ & 98.0 & $\theta_{2_{2}}$ \\
Lower Arm & $2_{3}$ & 25.8 & $\theta_{2_{3}}$ \\
Upper Arm & $2_{4}$ & 33.5 & $\theta_{2_{4}}$ \\
Head and Neck & 5 & 32.4 & $\theta_{5}$ \\
\hline
\end{tabular}

Figure 2 was the proposed model which clearly describe the motion and suitable for the kinematics analysis. The various segments; shank, thigh, trunk, feet to support distance, support, lower arm upper arm and head and neck segments were represented as $11,12,13,21,22,23,24$ and 5 respectively in the figure. And the angles $\theta_{1_{1}}, \theta_{1_{2}}, \theta_{1_{3}}, \theta_{2_{1}}, \theta_{2_{2}}, \theta_{2_{3}}, \theta_{2_{4}}$, and $\theta_{5}$ were Theta 11 , Theta 12 , Theta 13 , Theta 23 , Theta 24 respectively. It comprise of a closed chain at the beginning. Hence, the structure forms a closed link at joint 0 , where it connects the first joints via links 1 (branch 1) and 2 (branch 2), and interconnections continue up to joint 5. Branch 1 is made up of links: 11, 12 and 13, while branch 2 comprises of links: 21, 22, 23 and 24. Both branches combine at joint 5 and after it was the link 5; the head-neck segment. The suitable joint as the cut joint for this condition was joint 5. Denavit-Hartenberg (DH) method is applied for the analysis and Table 3 shows the DH parameters of the proposed sit-to-stand model. The equation constituting the direct kinematics for the above scenario can be obtained using Equation (1) [27].

Where; $T_{m}^{0}(q)$ is the overall transformation matrix which gives the kinematics equation, $A_{i}^{0}$ are the sequential transformation within the closed chain and $A_{m}^{i}$, are the transformations after the closed loop chain.

The process of computing $T_{m}^{0}(q)$ is usually achieved in stages: First a suitable joint is selected in the closed chain region, the homogenous transformations are then determined by applying the $\mathrm{DH}$ principle for each of the frames branches, determine the equality constraints for the frames such that it resulted in lower number of joint variables and finally the overall transformation is computed by combining that of the closed loop chain obtained and others (which are multiplied).

$$
T_{m}^{0}(q)=A_{i}^{0} A_{m}^{i}
$$

The terms $A^{i}$ are vector multiplication of certain properties of the DH parameters which are; the rotation of the link about the z-axis $\left(\right.$ Rotation $\left._{z, \theta_{i}}\right)$ the extent of which is given by the joint angle $\left(\theta_{i}\right)$, translation along the z-axis $\left(\right.$ Translation $_{z, d_{i}}$ ) referred to as the link offset $d_{i}$, translation on the x-axis 
(Translation $\left.{ }_{x, a_{i}}\right)$ which corresponds to the link length $\left(a_{i}\right)$ and finally the rotation of link about the $\mathrm{x}$-axis $\left(\right.$ Rotation $\left._{x, \alpha_{i}}\right)$ measured as the link twist $\left(\propto_{i}\right)$.

$$
A^{i}=\left(\text { Rotation }_{z, \theta_{i}}\right) x\left(\text { Translation }_{z, d_{i}}\right) x\left(\text { Translation }_{x, a_{i}}\right) x\left(\text { Rotation }_{x, \alpha_{i}}\right)
$$

In order to make the matrices more compact, sin and cos were represented by s and c respectively.

$$
A^{i}=\left[\begin{array}{cccc}
c \theta_{i} & -s \theta_{i} c \alpha_{i} & s \theta_{i} s \alpha_{i} & a_{i} c \theta_{i} \\
s \theta_{i} & c \theta_{i} c \alpha_{i} & -c \theta_{i} s \alpha_{i} & a_{i} s \theta_{i} \\
0 & s \alpha_{i} & c \alpha_{i} & d_{i} \\
0 & 0 & 0 & 1
\end{array}\right]
$$

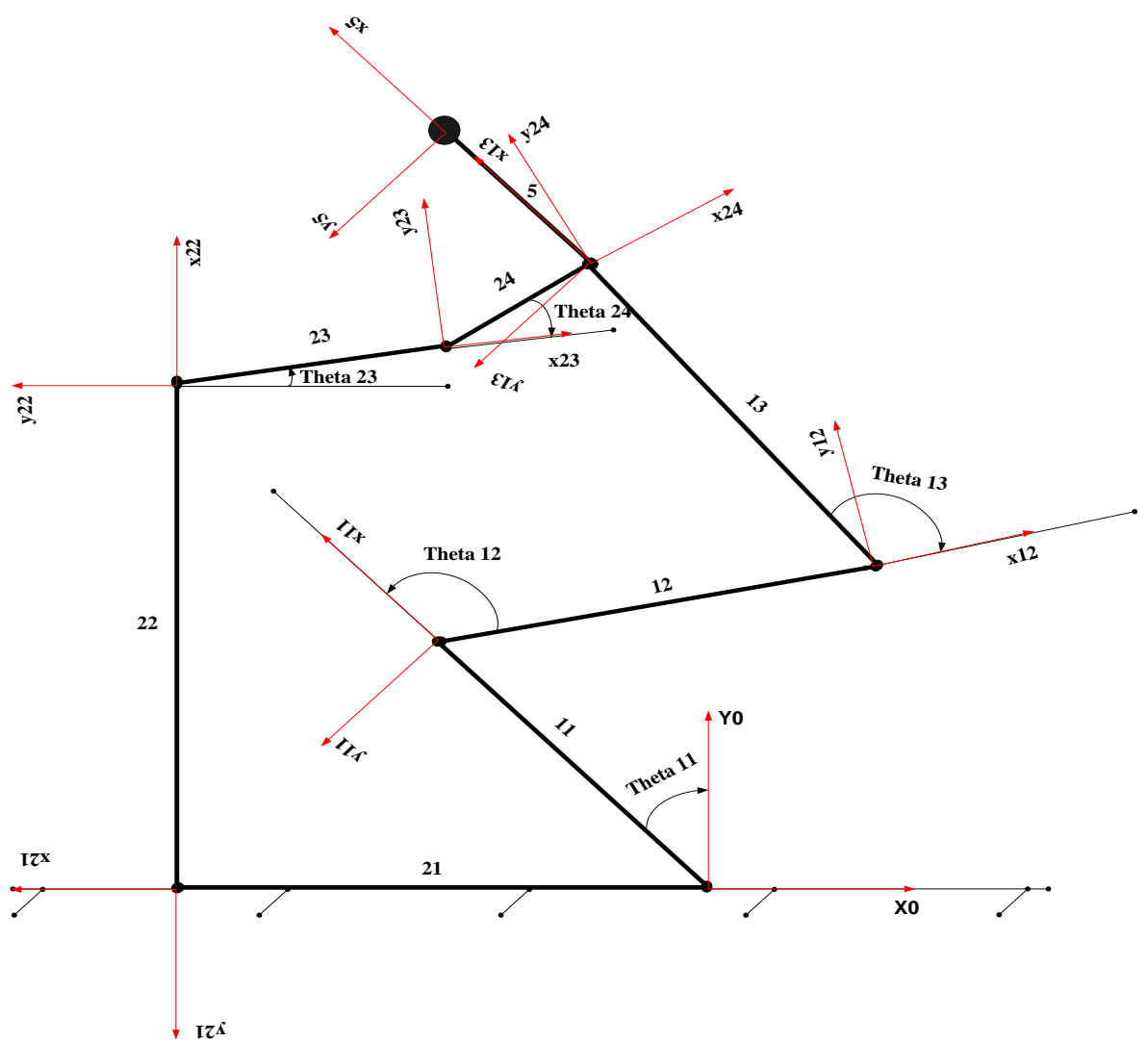

Figure 2. Joint kinematic convention for the FES assisted sit-to-stand model

Table 3. DH Parameters of the Model

\begin{tabular}{ccccc}
\hline Link & $a_{i}$ & $\alpha_{i}$ & $d_{i}$ & $\theta_{i}$ \\
\hline $1_{1}$ & $\mathrm{a} 1_{1}$ & 0 & 0 & $\theta_{1_{1}}$ \\
$1_{2}$ & $\mathrm{a} 1_{2}$ & 0 & 0 & $\theta_{1_{2}}$ \\
$1_{3}$ & $\mathrm{a} 1_{3}$ & 0 & 0 & $\theta_{1_{3}}$ \\
$2_{1}$ & $\mathrm{a} 2_{1}$ & 0 & 0 & $180^{0}$ \\
$2_{2}$ & $\mathrm{a} 2_{2}$ & 0 & 0 & $270^{0}$ \\
$2_{3}$ & $\mathrm{a} 2_{3}$ & 0 & 0 & $\theta_{2_{3}}$ \\
$2_{4}$ & $\mathrm{a} 2_{4}$ & 0 & 0 & $\theta_{2_{4}}$ \\
5 & $\mathrm{a} 5$ & 0 & 0 & 0 \\
\hline
\end{tabular}

Coordinate transformation for branch 1 frames was obtained as shown in (4) and it involves links $1_{1}, 1_{2}$ and $1_{3}$. 


$$
\begin{aligned}
& A_{1_{3}}^{0}\left(q_{1}\right)=A_{1_{1}}^{0} A_{1_{2}}^{1_{1}} A_{1_{3}}^{1_{2}}=\left[\begin{array}{cccc}
c_{1_{1} 1_{2} 1_{3}} & -s_{1_{1} 1_{2} 1_{3}} & 0 & a_{1_{1}} c_{1_{1}}+a_{1_{2}} c_{1_{1} 1_{2}}+a_{1_{3}} c_{1_{1} 1_{2} 1_{3}} \\
s_{1_{1} 1_{2} 1_{3}} & s_{1} 1_{2} 1_{3} & 0 & a_{1_{1}} s_{1_{1}}+a_{1_{2}} s_{1_{1} 1_{2}}+a_{1_{3}} s_{1_{1} 1_{2} 1_{3}} \\
0 & 0 & 1 & 0 \\
0 & 0 & 0 & 1
\end{array}\right] \\
& q_{1}=\left[\begin{array}{l}
\theta_{1_{1}} \\
\theta_{1_{2}} \\
\theta_{1_{3}}
\end{array}\right]
\end{aligned}
$$

Coordinate transformation for branch 2 frames was obtained as given by (6) which involve links $2_{1}, 2_{2}, 2_{3}$ and 2.

$$
\begin{aligned}
& A_{2_{4}}^{0}\left(q_{2}\right)=A_{2_{1}}^{0} A_{2_{2}}^{2_{1}} A_{2_{3}}^{2_{2}} A_{2_{4}}^{2_{3}}=\left[\begin{array}{cccc}
s_{2_{3} 2_{4}} & c_{2_{3} 2_{4}} & 0 & -a_{2_{1}}+a_{2_{3}} s_{2_{3}}+a_{2_{4}} s_{2_{3} 2_{4}} \\
-c_{2_{3} 2_{4}} & s_{2_{3} 2_{4}} & 0 & -a_{2_{2}}-a_{2_{3}} s_{2_{3}}-a_{2_{4}} c_{2_{3} 2_{4}} \\
0 & 0 & 1 & 0 \\
0 & 0 & 0 & 1
\end{array}\right] \\
& q_{2}=\left[\begin{array}{c}
180^{0} \\
270^{0} \\
\theta_{2_{3}} \\
\theta_{2_{4}}
\end{array}\right]
\end{aligned}
$$

The constant homogenous transformation for the final link is given by;

$$
A_{5}^{1_{3}}=\left[\begin{array}{cccc}
1 & 0 & 0 & a_{5} \\
0 & 1 & 0 & 0 \\
0 & 0 & 1 & 0 \\
0 & 0 & 0 & 1
\end{array}\right]
$$

In order to satisfy the constraints; that is at the meeting joint (point/joint 5) the coordinates of both branches at any instant should be same. Therefore, if subtracted for the branches will be zero ( i.e. $d_{2_{4} 1_{3}}=0$ ) and this may reduce the burden of computation or analysis by lowering the number of joint variables, that is no need to use all joints parameters [27], [36].

$$
R_{0}^{2_{4}}\left(q_{2}\right)\left(p_{2_{4}}^{0}\left(q_{2}\right)-p_{1_{3}}^{0}\left(q_{1}\right)\right)=\left[\begin{array}{lll}
0 & 0 & 0
\end{array}\right]^{T}
$$

The branches without any adjustment satisfied the above constraint, therefore any of the branches can be used. Therefore, for simplicity as well as relevance, branch 1 was chosen and that makes Equation (10) the required kinematics equation (model).

$$
\begin{aligned}
& T_{5}^{0}(q)=A_{1_{3}}^{0}(q) A_{5}^{1_{3}}(q)=\left[\begin{array}{cccc}
c_{1_{1} 1_{2} 1_{3}} & -s_{1_{1} 1_{2} 1_{3}} & 0 & a_{1_{1}} c_{1_{1}}+a_{1_{2}} c_{1_{1} 1_{2}}+a_{1_{3}} c_{1_{1} 1_{2} 1_{3}}+a_{5} c_{1_{1} 1_{2} 1_{3}} \\
s_{1_{1} 1_{2} 1_{3}} & c_{1_{1} 1_{2} 1_{3}} & 0 & a_{1_{1}} s_{1_{1}}+a_{1_{2}} s_{1_{1} 1_{2}}+a_{1_{3}} s_{1_{1} 1_{2} 1_{3}}+a_{5} s_{1_{1} 1_{2} 1_{3}} \\
0 & 0 & 1 & 0 \\
0 & 0 & 0 & 1
\end{array}\right] \\
& P_{5}^{0}=T_{5}^{0} P_{5}^{5}
\end{aligned}
$$


$P_{5}^{0}$; gives the coordinates with reference to the zero frame (reference frame), $P_{5}^{5}$ are the coordinates with reference the fifth frame that is the final frame (end-effector frame) and $T_{5}^{0}$ is given by Equation (10), that is; the transformation matrix.

In robotics, path describes the motion of a robot geometrically only, hence it remains silent about the system dynamics. Path simply specifies the locus of points within a specified operational or joint domain. On the other hand the trajectory is the time domain description of the movement and system dynamics are also captured when needed such as velocity and acceleration. Therefore, it is a time dependent path. Usually the trajectory is planned which can be done using algorithms. The algorithms describe the path, also incorporated are the constraints of both the path as well as that of dynamics. Results of which are the trajectories in relation to time for positions, velocities and accelerations reached [26], [27].

\section{RESULTS AND DISCUSSION}

It can be seen from Figure 2 that the complete movement model has 6 DOF which was obtained using the Grübbler's approach. According to the method number of DOF of any given structure can be obtained using Equations (12) and (13) [35]. Where: DOF; is the number of degrees of freedom, n; rigid body number of degrees of freedom, $\mathrm{M}$; the number of links, $\mathrm{J}$; the number of joints, $c_{k}$; the number of contraints on a given joint $\mathrm{k}$, and $f_{k}$; joint $\mathrm{k}$ number of freedom. Applying to Figure 2: $\mathrm{n}$ equals 3 (planer mechanism), $\mathrm{M}$ equals $8, \mathrm{~J}$ equals 7 and $\mathrm{f}$ equals 1 for all the revolute joints except the fixed joint which is 0 . Hence, on substituting in (12) and (13) appropriately, DOF was obtained as 6.

$$
\begin{aligned}
& \text { DOF }=n(M-1)-\sum_{k=1}^{J} c_{k} \\
& c_{k}=n-f_{k}
\end{aligned}
$$

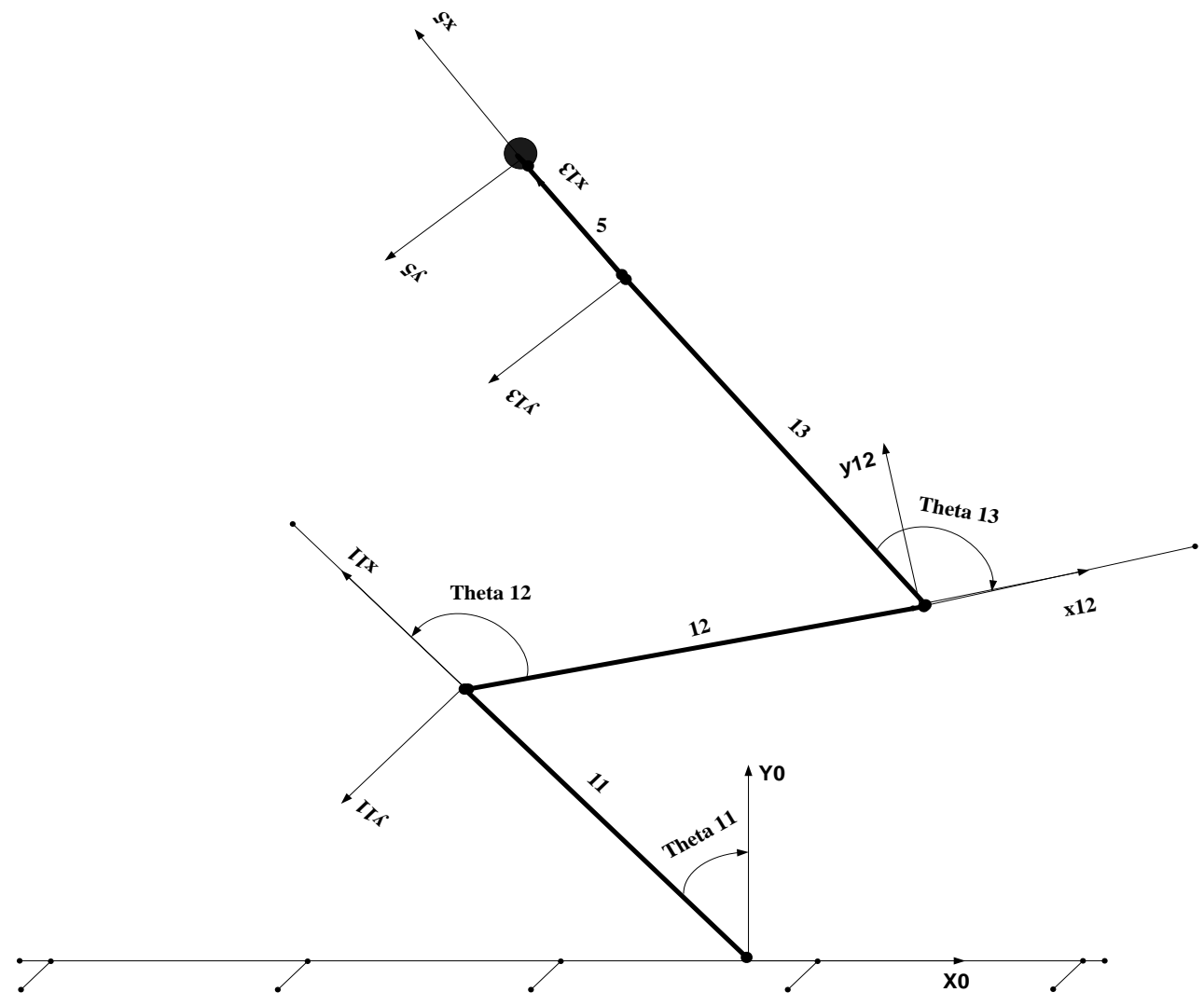

Figure 3. Joint kinematic convention for the approximated FES assisted sit-to-stand model

Therefore the mathematical representation would involve all the eight segments of the structure. Its transformation would be combination Equations (4), (6) and (8). The robotics principle had aid in reducing it 
to 4 DOF via Equation (9) and led to the mathematical model involving only four segments as illustrated by Figure 3. The transformation only involves Equations (6) and (8). The number of the DOF can be determined using the formular as well. Hence, reducing the model complexity.

The paths of the joints associated with the sit to stand movement can be obtained from Equation (10). Hence, the coordinates of the knee joint, hip joint, neck joint and the head with respect the reference frame are given by Equations (14), (15), (16) and (17) respectively. And the associated angles considered were five points from the sit to the stand positions and are as described by Equations (18)-(22).

$$
\begin{aligned}
& x_{1_{1}}^{0}=a_{1_{1}} c_{1_{1}} ; y_{1_{1}}^{0}=a_{1_{1}} s_{1_{1}} \\
& x_{1_{2}}^{0}=a_{1_{1}} c_{1_{1}}+a_{1_{2}} c_{1_{2}} ; y_{1_{2}}^{0}=a_{1_{1}} s_{1_{1}}+a_{1_{2}} s_{1_{2}} \\
& x_{1_{3}}^{0}=a_{1_{1}} c_{1_{1}}+a_{1_{2}} c_{1_{2}}+a_{1_{3}} c_{1_{3}} ; y_{1_{3}}^{0}=a_{1_{1}} s_{1_{1}}+a_{1_{2}} s_{1_{2}}+a_{1_{3}} s_{1_{3}} \\
& x_{5}^{0}=a_{1_{1}} c_{1_{1}}+a_{1_{2}} c_{1_{2}}+a_{1_{3}} c_{1_{3}}+a_{5} c_{1_{1} 1_{2} 1_{3}} ; y_{5}^{0}=a_{1_{1}} s_{1_{1}}+a_{1_{2}} s_{1_{2}}+a_{1_{3}} s_{1_{3}}+a_{5} s_{1_{1} 1_{2} 1_{3}} \\
& q(\theta)=\left[\begin{array}{llll}
\theta_{1_{1}} & \theta_{1_{2}} & \theta_{1_{3}} & \theta_{5}
\end{array}\right] \\
& \theta_{1_{1}}=\left[105^{0} 101.25^{0} 97.5^{0} 93.75^{0} 90^{0}\right] \\
& \theta_{1_{2}}=\left[278^{0} 298.5^{0} 319^{0} 339.5^{0} 360^{0}\right] \\
& \theta_{1_{3}}=\left[75^{0} 56.25^{0} 37.5^{0} 18.75^{0} 0^{0}\right] \\
& \theta_{5}=\left[\begin{array}{lllll}
0^{0} & 0^{0} & 0^{0} & 0^{0} & 0^{0}
\end{array}\right]
\end{aligned}
$$

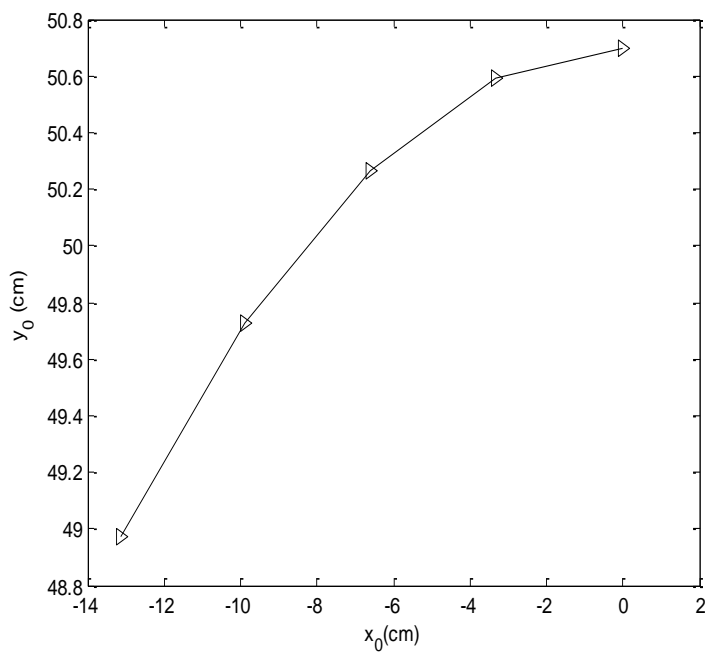

Figure 4. Knee joint locus in the fixed frame during the movement

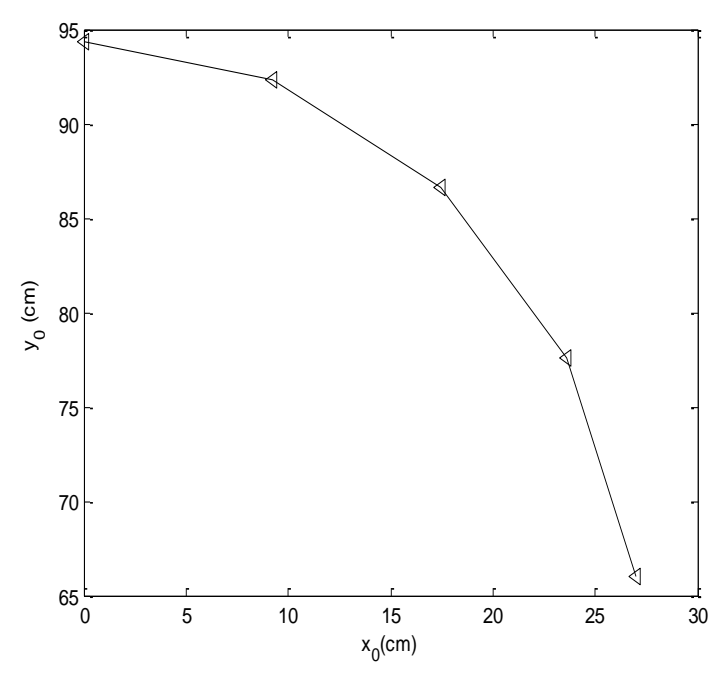

Figure 5. Hip joint locus in the fixed frame during the movement

Figure 4, Figure 5 and Figure 6 show the paths/loci of the knee, hip and neck joints respectively, with reference to the fixed frame during the sit-to-stand movements from the initial to the final positions. Figure 7 shows that of the head during the transition, it indicates how the height changes during movement. All the paths were given with reference to the reference or zero frame. It can be clearly seen that the desired paths were obtained which means the concept can be continued and the next stage would be determining the dynamic model. The model can be used for control system design as well as stability analysis. 


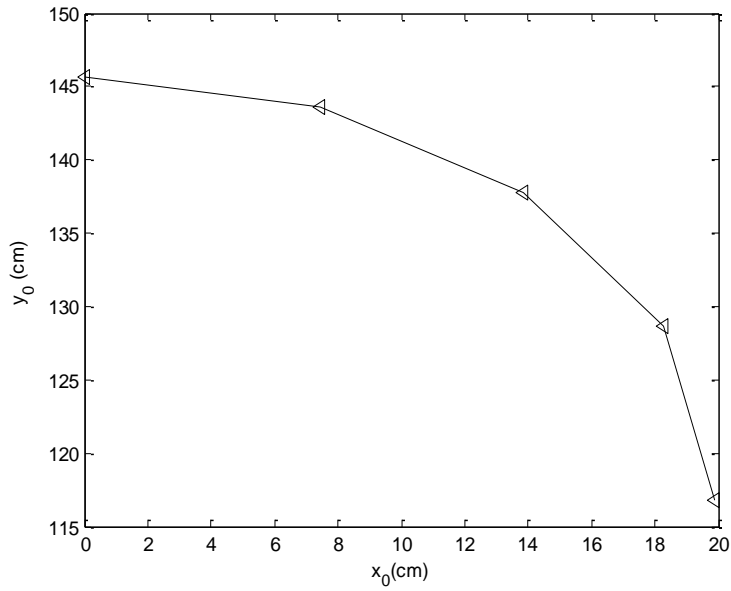

Figure 6. Neck joint locus in the fixed frame during the movement

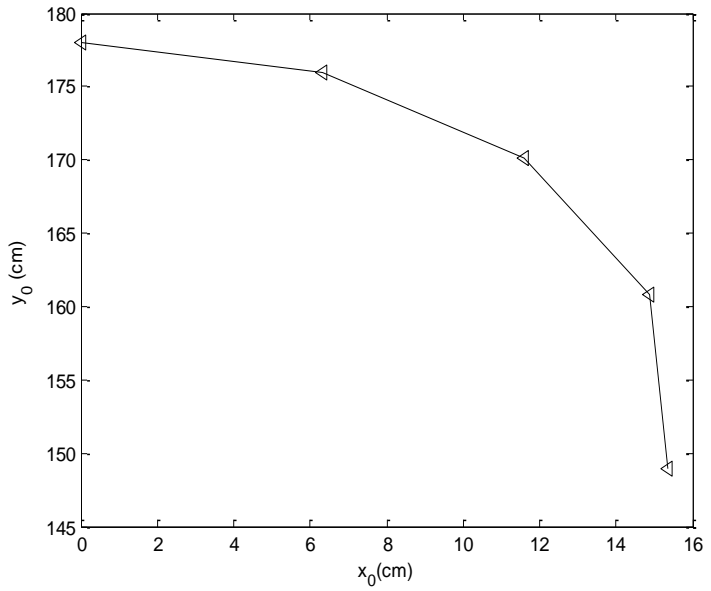

Figure 7. Head locus in the fixed frame during the movement

\section{CONCLUSION}

Kinematic model is the first step towards developing the dynamic model. Besides constituting the initial building block for the desired dynamic model, the kinematic model also serves to facilitate the study of various kinematic feasibilities. The dynamic modelling which is usually more tasking can then be developed and it aids as well in obtaining a configuration with minimal complexity.

The study showed that the 6 DOF closed chain FES aided sit-to-stand maneuver idea could be implemented conveniently using 4 DOF. Although both branches can be used to achieve the desired movement goal but branch 2 is easier for analysis. It is because it has its first two links fixed from the reference, but branch 1 was more relevant because it has the joint to be stimulated which is the basis of the research. Reason of this assertion was as shown that no additional constrain is needed as depicted after applying Equation (9) [27], [36] and the loci in Figure 4, Figure 5, Figure 6 and Figure 7 give the intended paths for the movement. It can be seen that the final points in Figure 6 correspond to the subject height. The 4 DOF has additional single joint compared to earlier works such as that of Fattah et al. [30] and Tsukahara et al. [31] models which makes it more accurate and flexible; accurate in the sense that it accommodates addition joint i.e. the neck joint and also more flexible in the sense that if future research uncover more contributions by the segments it can be easily incorporated most especially that of the truck, neck and upper limbs.

The work is novel in the sense that it is an improvement over the existing models. And additionally others are; making it a more gray model (by adding more experimental findings) and adding an outcome indicating that about $10 \%$ of the weight is supported by the upper limbs in paraplegics [37]. It would be incorporated in the dynamic modelling prior to other studies i. e. controller design and stability analysis.

\section{ACKNOWLEDGEMENTS}

"This paper was partly sponsored by the Centre of Graduate Studies UTHM, Office for Research, Innovation, Commercialization and Consultancy Management, UTHM and ATBU".

\section{REFERENCES}

[1] S. Jezernik, P. Inderbitzin, T. Keller, and R. Riener, "A novel sliding mode controller for functional electrical stimulation," in Proceedings of the 15th IFAC World Congress on Automatic Control, Barcelona Session slot TMo-M20: Modelling and Control in Biomedical Systems, 2002.

[2] W. K. Durfee, "Gait restoration by functional electrical stimulation," in Climbing and Walking Robots, ed: Springer, 2006, pp. 19-26.

[3] Y. Chen, J. Hu, L. Peng, and Z.-g. Hou, "The FES-assisted control for a lower limb rehabilitation robot: simulation and experiment," Robotics and Biomimetics, vol. 1, pp. 1-20, 2014.

[4] N. Arantes, D. Vaz, M. Mancini, M. Pereira, F. Pinto, and T. Pinto, "Effects of functional electrical stimulation applied to the wrist and finger muscles of hemiparetic subjects: a systematic review of the literature," Brazilian Journal of Physical Therapy, vol. 11, pp. 419-427, 2007. 
[5] G. P. Braz, M. Russold, and G. M. Davis, "Functional electrical stimulation control of standing and stepping after spinal cord injury: A review of technical characteristics," Neuromodulation: Technology at the Neural Interface, vol. 12, pp. 180-190, 2009.

[6] H. Kern, U. Carraro, N. Adami, D. Biral, C. Hofer, C. Forstner, et al., "Home-based functional electrical stimulation rescues permanently denervated muscles in paraplegic patients with complete lower motor neuron lesion," Neurorehabilitation and neural repair, 2010.

[7] A. Papachristos, "Functional Electrical Stimulation in Paraplegia," in Topics in Paraplegia, Y. Dionyssiotis, Ed., ed, 2014, pp. 109-126.

[8] J. F. Tan, K. Masani, A. H. Vette, J. Zariffa, M. Robinson, C. Lynch, et al., "Inverted pendulum standing apparatus for investigating closed-loop control of ankle joint muscle contractions during functional electrical stimulation," International Scholarly Research Notices, vol. 2014, 2014.

[9] P. J. Grahn, G. W. Mallory, B. M. Berry, J. T. Hachmann, D. A. Lobel, and J. L. Lujan, "Restoration of motor function following spinal cord injury via optimal control of intraspinal microstimulation: toward a next generation closed-loop neural prosthesis," Frontiers in neuroscience, vol. 8, 2014.

[10] A. K. Vafadar, J. N. Côté, and P. S. Archambault, "Effectiveness of functional electrical stimulation in improving clinical outcomes in the upper arm following stroke: a systematic review and meta-analysis," BioMed research international, vol. 2015, 2015.

[11] K. Masani and M. R. Popovic, "Functional electrical stimulation in rehabilitation and neurorehabilitation," in Springer handbook of medical technology, ed: Springer, 2011, pp. 877-896.

[12] A. Officer, T. Shakespeare, P. von Groote, J. Bickenbach, and W. H. Organization, International perspectives on spinal cord injury: World Health Organization, 2013.

[13] W. H. Organization, Neurological disorders: public health challenges: World Health Organization, 2006.

[14] M. O. Ibitoye, N. A. Hamzaid, N. Hasnan, A. K. A. Wahab, and G. M. Davis, "Strategies for rapid muscle fatigue reduction during FES exercise in individuals with spinal cord injury: a systematic review," PloS one, vol. 11, p. e0149024, 2016

[15] M. O. Ibitoye, N. A. Hamzaid, J. M. Zuniga, N. Hasnan, and A. K. A. Wahab, "Mechanomyographic parameter extraction methods: an appraisal for clinical applications," Sensors, vol. 14, pp. 22940-22970, 2014.

[16] M. O. Ibitoye, N. A. Hamzaid, J. M. Zuniga, and A. K. A. Wahab, "Mechanomyography and muscle function assessment: A review of current state and prospects," Clinical Biomechanics, vol. 29, pp. 691-704, 2014.

[17] M. J. Dolan, B. J. Andrews, and P. Veltink, "Switching curve controller for FES-assisted standing up and sitting down," IEEE Transactions on Rehabilitation Engineering, vol. 6, pp. 167-171, 1998.

[18] N.-Y. Yu, J.-J. J. Chen, and M. S. Ju, "Closed-loop control of quadriceps/hamstring activation for FES-induced standing-up movement of paraplegics," Journal of Musculoskeletal Research, vol. 5, pp. 173-184, 2001.

[19] C. Lynch and M. Popovic, "Closed-loop control for FES: Past work and future directions," in 10th Annual Conference of the International FES Society, 2005, pp. 2-4.

[20] M. Poboroniuc, S. , "New experimental results on feedback control of FES-based standing in paraplegia," AL.I.CUZA University Scientific Annals of Biophysics, Medical Physics and Environment Physics, tom.I, , vol. vol. III, pp. 83-89, 2007.

[21] R. Davoodi and B. J. Andrews, "Computer simulation of FES standing up in paraplegia: A self-adaptive fuzzy controller with reinforcement learning," IEEE Transactions on Rehabilitation Engineering, vol. 6, pp. 151-161, 1998.

[22] R. Davoodi and B. J. Andrews, "Optimal control of FES-assisted standing up in paraplegia using genetic algorithms," Medical engineering \& physics, vol. 21, pp. 609-617, 1999.

[23] M. Huq and M. Tokhi, "Genetic algorithms based approach for designing spring brake orthosis-Part II: Control of FES induced movement," Applied Bionics and Biomechanics, vol. 9, pp. 317-331, 2012.

[24] F. Previdi, M. Ferrarin, S. M. Savaresi, and S. Bittanti, "Closed-loop control of FES supported standing up and sitting down using Virtual Reference Feedback Tuning," Control Engineering Practice, vol. 13, pp. 1173-1182, 2005.

[25] R. M. Esfanjani and F. Towhidkhah, "Application of nonlinear model predictive controller for FES-assisted standing up in paraplegia," in Engineering in Medicine and Biology Society, 2005. IEEE-EMBS 2005. 27th Annual International Conference of the, 2006, pp. 6210-6213.

[26] M. W. Spong, S. Hutchinson, and M. Vidyasagar, Robot modeling and control: Wiley New York, 2006.

[27] B. Siciliano, L. Sciavicco, L. Villani, and G. Oriolo, Robotics: modelling, planning and control: Springer Science \& Business Media, 2010.

[28] S. Nuzik, R. Lamb, A. VanSant, and S. Hirt, "Sit-to-stand movement pattern," Physical Therapy, vol. 66, pp. 1708$1713,1986$.

[29] R. Kamnik, J. Q. Shi, R. Murray-Smith, and T. Bajd, "Nonlinear modeling of FES-supported standing-up in paraplegia for selection of feedback sensors," IEEE Transactions on Neural Systems and Rehabilitation Engineering, vol. 13, pp. 40-52, 2005.

[30] A. Fattah, M. Hajiaghamemar, and A. Mokhtarian, "Design of a Semi-Active Semi-Passive Assistive Device for Sitto-Stand Tasks," presented at the 16 th Annual (International) Conference on Mechanical Engineering-ISME2008, May 14-16, 2008, Shahid Bahonar University of Kerman, Iran, 2008.

[31] A. Tsukahara, R. Kawanishi, Y. Hasegawa, and Y. Sankai, "Sit-to-stand and stand-to-sit transfer support for complete paraplegic patients with robot suit HAL," Advanced robotics, vol. 24, pp. 1615-1638, 2010. 
[32] C. A. Stevermer and J. C. Gillette, "Kinematic and Kinetic Indicators of Sit-to-Stand," Journal of applied biomechanics, vol. 32, pp. 7-15, 2016.

[33] D. A. Winter, Biomechanics and motor control of human movement: John Wiley \& Sons, 2009.

[34] M. Ferrarin and A. Pedotti, "The relationship between electrical stimulus and joint torque: A dynamic model," IEEE transactions on rehabilitation engineering, vol. 8, pp. 342-352, 2000.

[35] K. Lynch and F. Park, Modern Robotics: Mechanics, Planning, and Control: Cambridge University Press, 2017.

[36] G. M. Freitas, A. C. Leite, and F. Lizarralde, "Kinematic control of constrained robotic systems," Sba: Controle \& Automação Sociedade Brasileira de Automatica, vol. 22, pp. 559-572, 2011.

[37] K. A. Bernhardt, L. A. Beck, J. L. Lamb, K. R. Kaufman, S. Amin, and L.-A. Wuermser, "Weight Bearing through Lower Limbs in a Standing Frame with and without Arm Support and Low-Magnitude Whole Body Vibration in Men and Women with Complete Motor Paraplegia," American journal of physical medicine \& rehabilitation/Association of Academic Physiatrists, vol. 91, p. 300, 2012.

\section{BIOGRAPHIES OF AUTHORS}

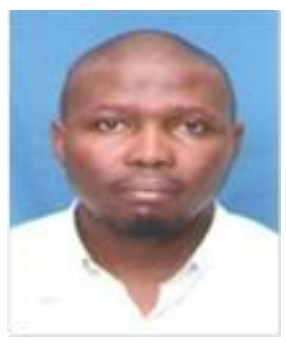

Mohammed Ahmed obtained both his Bachelor and Master Degrees in Electrical/Electronics Engineering at Abubakar Tafawa Balewa University, Bauchi, Nigeria. He is currently pursuing his PhD.

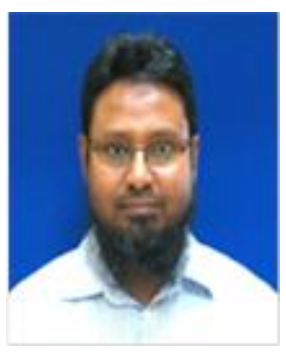

Dr. Mohammad Saiful Huq received his Doctor of Phylosophy in Control Systems Engineering at the University of Sheffield, UK. He currently works as a lecturer at Universiti Tun Hussein Onn Malaysia.

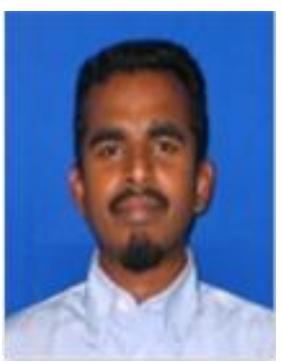

Dr. Babul Salam KSM Kader Ibrahim received: Certificate in Electrical Power Engineering at Politeknik Port Dickson, Bachelor of Electrical Engineeng at Kolej Universiti Tun Hussein Onn (Currently Universiti Tun Hussein Onn Malaysia), Master of Engineering (ElectricalMechatronic) at Universiti Technology Malaysia and Doctor of Phylosophy in Control Systems Engineering at the University of Sheffield, UK. He is a lecturer at Universiti Tun Hussein Onn Malaysia. 